\title{
ENGINEERING UNDERGRADUATES AND THEIR SELF- REPORTED CONFIDENCE AND PROFICIENCY LEVELS IN LIFELONG LEARNING (A12)
}

\author{
Kathryn Marcynuk, Vanier Scholar, Anne Parker, Ph.D., and Norma Godavari, M.L.I.S. \\ Centre for Engineering Professional Practice and Engineering Education \\ University of Manitoba \\ Kathryn.Marcynuk@umanitoba.ca; Anne.Parker@umanitoba.ca
}

\begin{abstract}
This paper reports on what we found when we surveyed second-year students in a Technical Communication class, once at the beginning of the semester and again at the end, and then when we surveyed two senior capstone design classes, one in Mechanical Engineering, one in Electrical and Computer Engineering, and one in Civil Engineering. In all these iterations, we asked students to indicate their levels of confidence and proficiency in their writing and speaking skills (communication skills), teamwork and personal skills development (lifelong learning).

When we surveyed our second-year students, they indicated that they were only moderately confident in their communication skills (the aggregate was mostly 3 or slightly more on a scale of 5). At the end of the semester, when we asked them what they believed would be the competency level expected of them in these areas when they graduated, that number jumped to 4.5 on average. These students, however, were also decidedly more confident in their teamwork and lifelong learning skills, where the average hovered close to 3.5. On average, the capstone students were likewise confident in these areas, even slightly more so (3.87).

Given the rapidity with which technical information grows and the complexity of the world around us, engineering students must be more prepared than ever to develop the drive to keep learning so that, as practicing professionals, they are equipped to maintain their competence and contribute to the advancement of knowledge.
\end{abstract}

Keywords: lifelong learning, self-efficacy, communication skills, professional practice, graduate attributes

\section{INTRODUCTION}

Our study began by focusing on the professional skills expected of our engineering students; specifically, writing and speaking, teamwork and lifelong learning. Given the growing volume of technical information with which engineers must contend, professional development in general and lifelong learning in particular have assumed an ever-increasing importance. With this is mind, we developed two surveys that looked at the professional skills in particular. In this paper, we will focus on lifelong learning.

In our study, we defined confidence as a belief in one's own ability to do a task, while proficiency reflects achievement or competence in actually doing that task. In the two surveys we administered to our second-year Technical Communication students from 2013 to 2015, one at the beginning of term and one at the end, we asked them to rate their current levels of confidence and proficiency in their writing and speaking skills, in their teamwork skills, and in their personal skills development - those skills related to lifelong learning ${ }^{1}$.

In 2017, we refreshed our study to include a Mechanical Engineering senior capstone design class where 82 students responded; in 2018, 55 students in the Electrical and Computer Engineering capstone class and 46 students in the Civil Engineering capstone class responded ${ }^{2}$. All these surveys were anonymous so that students could not be matched to particular survey results or to grades in the class.

Interestingly, when some American college students were asked whether they were confident in their speaking and writing abilities, as well as their academic ability in general, they indicated that they were indeed confident; they saw themselves as above average ${ }^{3}$. However, while our students were less confident when it came to their writing and speaking skills, they were decidedly more confident in their lifelong learning skills, defined as the "ability to identify and to address their own educational needs in a changing world in ways sufficient 
to maintain their competence and to allow them to contribute to the advancement of knowledge"4. Doing so means they must be able to devise ways to achieve these outcomes $^{5}$ and, as well, be self-aware enough to recognize their own strengths and weaknesses ${ }^{1}$.

\section{METHODOLOGY}

We chose to survey these student cohorts in order to gain an insight into their confidence in their own ability to practice lifelong learning, as well as other professional skills, since some studies suggest that a growth in confidence can lead to greater academic success $^{6}$; if students believe in their ability to do a task, then there is a greater likelihood that they will be successful in actually doing it. The twenty-question survey was given to eleven cohorts of students (most of whom were at different stages in their engineering undergraduate programs) over a period of six years; our intent was to see what levels of confidence they had at this point in their lives.

We designed a survey in order to gather data on students' self-reported levels of confidence in communication, teamwork, and lifelong learning skills. To assess these skills, we identified twenty tasks that would demonstrate competence in one of the skills of interest: five written communication tasks, five oral communication tasks, six tasks that occur in effective teamwork, and four tasks related to learning beyond the classroom. The individual tasks were not explicitly linked to the skill categories on the survey sheets that students were given.

\subsection{The Survey}

The four tasks related to lifelong learning (questions 17-20 on the survey) were:

(Q17) identifying your own personal areas of strengths \& weaknesses

(Q18) identifying the means to develop your strengths and eliminate your weaknesses

(Q19) continuing to learn and expand your knowledge after you complete your B.Sc. in Engineering

(Q20) applying critical inquiry and analysis to engineering problems and doing the communications that support engineering work

Depending on the iteration of the survey, students were asked to rate their own confidence or proficiency in being able to perform each task. The second-year students surveyed at the beginning of the semester were asked to rate their current confidence level for each task, as they had not yet had the opportunity to learn or practice the skills. At the end of the same semester, the second-year students were asked to rate their current level of proficiency in the same tasks, as well as to speculate on the expected level of proficiency that they would need to achieve for each task by graduation. All of the senior capstone students surveyed were only asked to rate their current level of proficiency in each task.

Students were asked to rate their confidence or proficiency level in each task using the CDIO five-level scale as a guideline ${ }^{7}$. The CDIO levels are:

1. to have experience or been exposed to

2. to be able to participate and contribute to

3. to be able to understand and explain

4. to be skilled in the practice or implementation of

5. to be able to lead or innovate in

Only the self-identified ratings from 1-5 were collected from students on the surveys. No names, comments or other information was solicited, and students were explicitly asked not to include any identifying information on their survey sheets so that everything would remain anonymous.

\subsection{The Participants}

The survey described in Section 2.1 was administered to students in four different undergraduate engineering courses at the University of Manitoba: ENG 2010 Technical Communication, Mechanical Engineering Capstone, Electrical \& Computer Engineering Capstone, and Civil Engineering Capstone.

The ENG 2010 Technical Communication class is a required second-year course for all Civil, Mechanical, and Electrical \& Computer Engineering students. The class itself uses a team-based approach. Students are grouped into teams of 4 or 5 students who work collaboratively over the semester to produce a research project on an engineering topic of interest to them. In this context, students must learn effective group interaction, including conflict resolution, along with effective time and project management.

Since individual progress is one measure of team performance, team members report on their progress on their assigned tasks, thereby taking stock of their individual productivity. This is just one way students are encouraged to reflect on how they can build on their strengths and mitigate their weaknesses - in other words, the beginning of lifelong learning as they move forward.

We gave the survey to nine cohorts of students in this class over seven consecutive semesters from January 2013 to April 2015. Students in this class were surveyed twice: once at the beginning of the semester, and again at its completion. Approximately 450 students completed the first of these surveys, while close to 370 students completed the second. The decrease in student participation may be attributable either to students dropping the course during the semester or choosing not to respond to the second survey.

The Mechanical Capstone course, consisting predominantly of senior graduating students, was surveyed once in the fall semester of 2017. A total of 82 
students in this class completed the survey. Similarly, the Electrical \& Computer Engineering Capstone course was surveyed once in the winter semester of 2018. In this class, 55 seniors completed the survey. In the same semester, 46 students in the Civil Engineering Capstone course also completed the survey.

\section{RESULTS \& OBSERVATIONS}

The average responses from each cohort for the four lifelong learning questions are shown in Table 1 . The overall average for each of those four questions, which can be thought of as students' overall confidence level in the skill of lifelong learning, is also shown in the first column of Table 1 .

Table 1: Survey results showing the average lifelong learning confidence level from each survey, and the average response to each of the four questions.

\begin{tabular}{|l|c|c|c|c|c|}
\hline & Avg & Q17 & Q18 & Q19 & Q20 \\
\hline $\begin{array}{l}\text { ENG 2010 } \\
\text { Survey 1 }\end{array}$ & 3.41 & 3.54 & 3.23 & 3.64 & 3.22 \\
\hline $\begin{array}{l}\text { ENG 2010 } \\
\text { Survey 2 }\end{array}$ & 3.55 & 3.66 & 3.47 & 3.58 & 3.48 \\
\hline $\begin{array}{l}\text { ENG 2010 } \\
\text { Expected } \\
\text { Graduation }\end{array}$ & 4.53 & 4.53 & 4.47 & 4.53 & 4.59 \\
\hline $\begin{array}{l}\text { ME } \\
\text { Capstone }\end{array}$ & 3.87 & 3.83 & 3.56 & 4.17 & 3.93 \\
\hline $\begin{array}{l}\text { ECE } \\
\text { Capstone }\end{array}$ & 3.44 & 3.51 & 3.25 & 3.65 & 3.35 \\
\hline $\begin{array}{l}\text { CVL } \\
\text { Capstone }\end{array}$ & 3.67 & 3.77 & 3.48 & 3.78 & 3.65 \\
\hline
\end{tabular}

Figure 1 shows that, in all cohorts, across all of the lifelong learning questions, students on average believed that their competency was higher than 3 on the CDIO scale. That is, they felt that they would, at a minimum, "be able to understand and explain" each of the particular lifelong learning tasks on the survey.

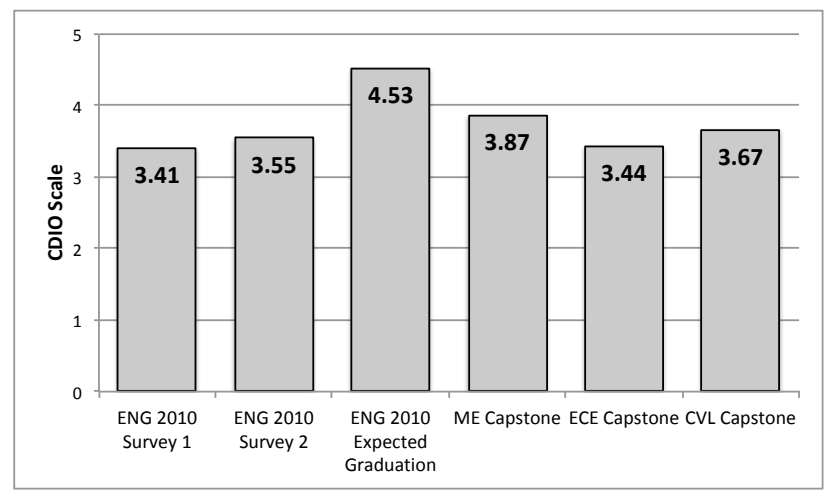

Figure 1: Average confidence level across all four lifelong learning tasks of each survey.
Figure 2 shows the confidence levels in each particular lifelong learning task in each cohort surveyed.

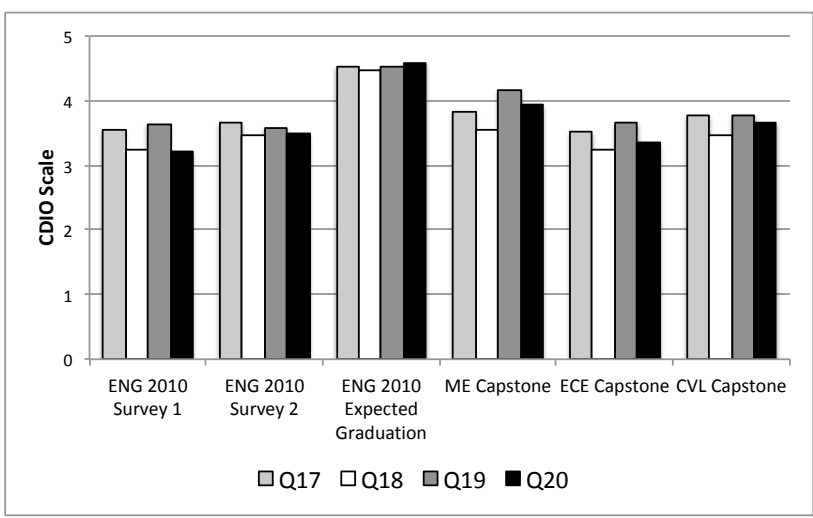

Figure 2: Confidence level in each of the four lifelong learning tasks grouped by survey.

The percentage of responses to all four questions (Q17-Q20) at each CDIO level are shown grouped by survey cohort in Figure 3. In each survey, students responded to the lifelong learning questions with $\mathrm{CDIO}$ Level 1 less than $5 \%$ of the time.

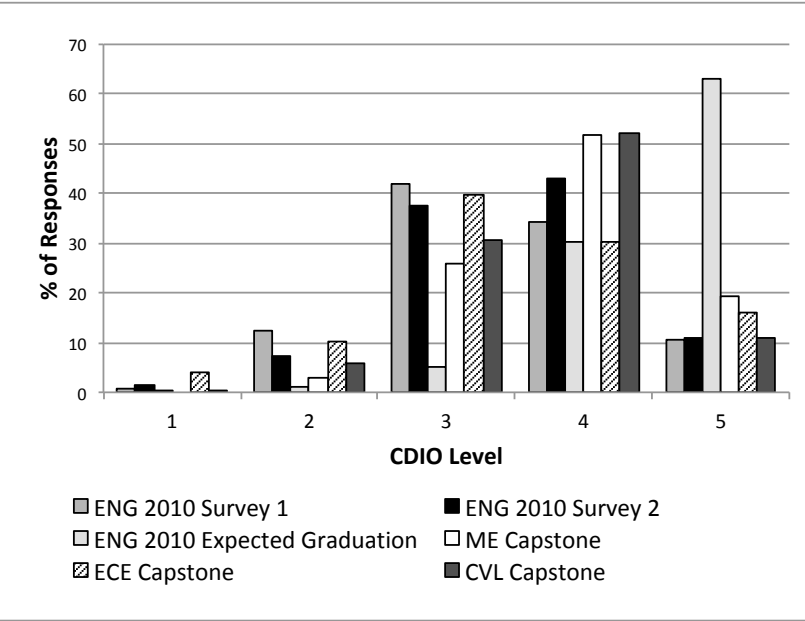

Figure 3: Percentage of responses at each CDIO level to all four lifelong learning tasks (Q17-Q20) for each cohort of students surveyed.

\subsection{The ENG 2010 Class}

The students in the second-year ENG 2010 Technical Communication course were asked to participate in the survey twice, at the beginning and end of the semester (these iterations were titled "Survey 1" and "Survey 2"). The overall average response to the four lifelong learning questions increased from the beginning to the end of the semester. The two questions with the largest gains were related to developing strengths and 
eliminating weaknesses (Q18) and applying critical analysis to engineering problems (Q20). The confidence level in both of these tasks increased by approximately one quarter of a CDIO level (an increase of 0.24 points and 0.26 points, respectively).

The second survey at the end of the semester also asked students to speculate on the level of proficiency that they would need in each task upon graduation from their program. The results in Table 1 and Figure 1 show that, on average, students had quite high expectations of their future selves in the area of lifelong learning. The average response for the lifelong learning questions was 4.53, almost a full point higher than where they currently rated their proficiency level. This increase indicates that students expected to at least "be skilled in the practice or implementation of" each of the lifelong learning tasks (a 4 on the CDIO scale) by graduation, and a sizeable number of the students expected "to be able to lead or innovate in" the tasks as well (a 5 on the CDIO scale). The task with the highest average expected proficiency upon graduation was also the ability to apply critical analysis to engineering problems (Q20).

Nine classes of ENG 2010 students were given these surveys over seven separate semesters. Figures 4-7 compare the average responses by question for these classes. In general, the average current level of confidence about each lifelong learning task was more varied in the first survey compared with the second.

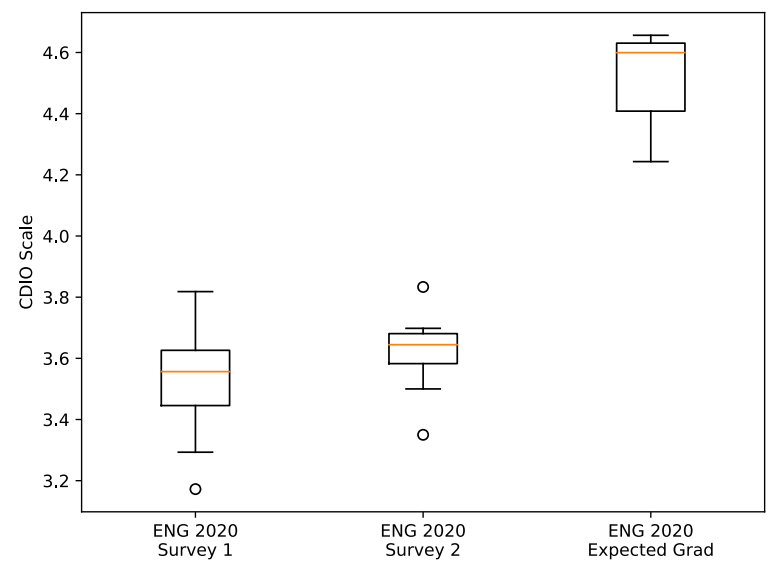

Figure 4: Average responses to the task of identifying your own personal areas of strengths \& weaknesses (Q17) across the nine classes of ENG 2010 students surveyed.

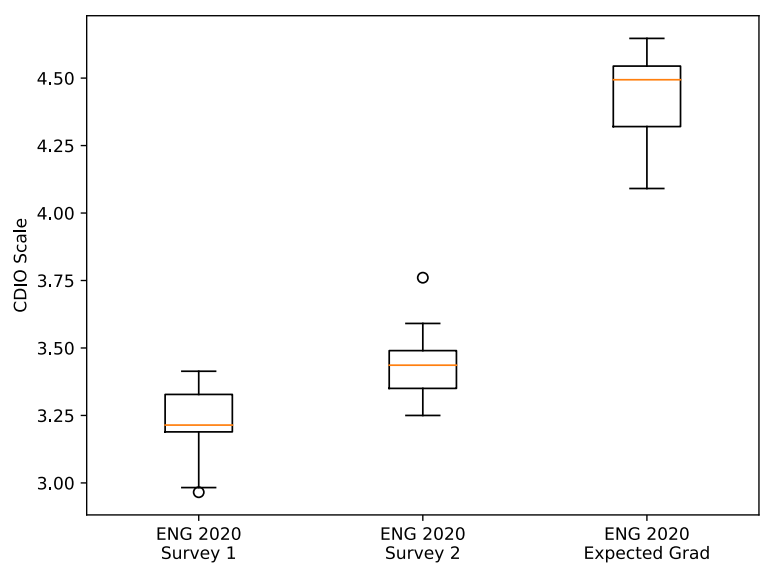

Figure 5: Average responses from each ENG 2010 class to the task of identifying the means to develop your strengths and eliminate your weaknesses (Q18).

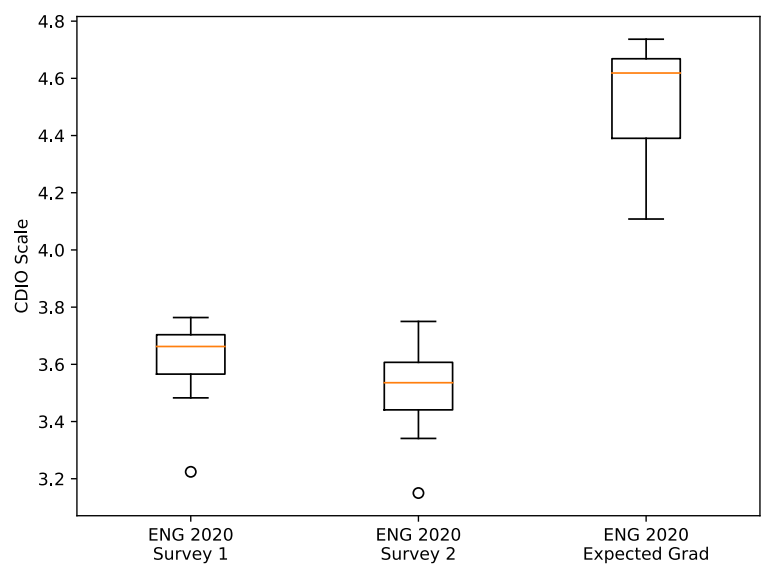

Figure 6: Average responses from each ENG 2010 class to the task of continuing to learn and expand your knowledge after you complete your B.Sc. (Q19).

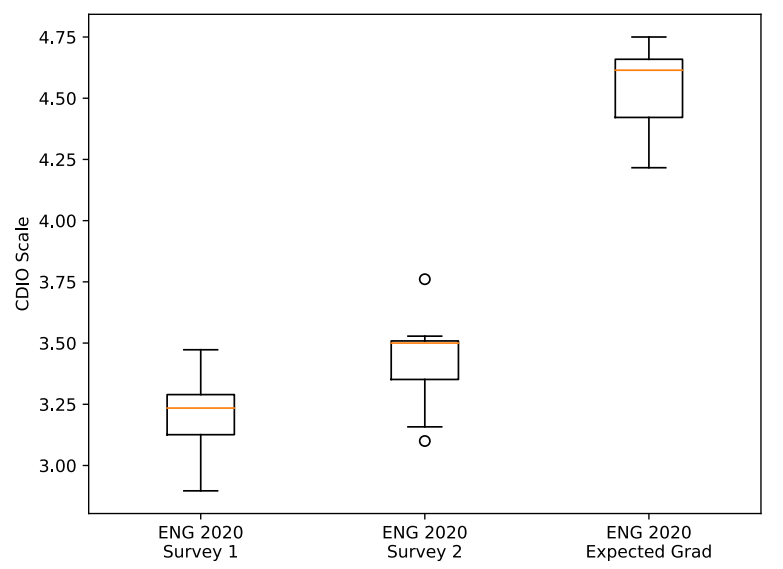

Figure 7: Average responses from each ENG 2010 class to the task of applying critical inquiry and analysis to engineering problems and doing the communications that support engineering work (Q20). 


\subsection{The Capstone Classes}

After seeing the expectations that the $2^{\text {nd }}$ year ENG 2010 class had for their future graduating selves, we were curious to see how proficient students actually felt in the same tasks near the end of their program. We surveyed one Mechanical Engineering, one Electrical \& Computer Engineering, and one Civil Engineering senior capstone design class, each of which is taken near the end of a student's undergraduate degree.

The capstone students didn't feel quite as proficient as the ENG 2010 classes had predicted they would for all of the lifelong learning tasks on the survey. However, the Mechanical Engineering capstone students self-identified proficiency levels that were still higher than the second-year students' current level for every one of the survey questions. In fact, the task of continuing to learn and expand their knowledge after completing their degree (Q19) had an average response of 4.17 from the Mechanical Engineering capstone students, indicating that they felt confident in the practice of this skill. The ability to apply critical analysis to engineering problems (Q20) was not far behind with a 3.93 average rating from the students.

The Civil Engineering Capstone students' selfidentified proficiency levels were, on average, also higher than the ENG 2010 students' current level for each of the survey questions. These students did not answer quite as confidently as their Mechanical Engineering peers. For the Civil Engineering students, the lifelong learning skills with the highest average responses were (Q17) at 3.77 and (Q19) at 3.78.

The results for the Electrical \& Computer Engineering capstone students were less informative. For all but one of the questions, the ECE capstone students rated their current proficiency to be less than that of their second-year counterparts at the end of the semester. The only task that the Electrical \& Computer capstone students rated higher was continuing to learn and expand their knowledge after completing their degree (Q19). The average response to this question was 3.65 , still only 0.07 points higher than the second-year students.

\subsection{Comparison of the Responses: ENG 2010 \& Capstone Classes}

In addition to comparing the survey responses of the predominately second-year ENG 2010 students with the responses of the senior capstone students, we were also interested in how each group's confidence in their own proficiency varied between the four lifelong learning tasks.

As shown in Figure 3, when asked to speculate on their future proficiency at graduation, ENG 2010 students responded with CDIO Level 5 over $60 \%$ of the time. This is markedly different from the number of capstone students who responded with a 5 on the CDIO scale for any of the four lifelong tasks. The Mechanical Engineering class had the highest percentage of responses at this level amongst the capstone classes, and only $20 \%$ of responses from this class were at CDIO Level 5. The most frequent responses from the capstone students were CDIO Level 4 from the Mechanical and Civil Engineering classes, and CDIO Level 3 from the Electrical \& Computer Engineering class.

However, on average, students in all of the cohorts felt sufficiently confident in their ability to, at a minimum, "understand or explain" each of the lifelong learning tasks (a 3 on the CDIO scale). However, amongst all participating survey groups, clear trends did emerge as to which of the four tasks ranked as the lowest and the highest levels of proficiency and confidence.

The task of "identifying the means to develop your strengths and eliminate your weaknesses" (Q18) had the lowest confidence score reported in all but one of the surveys. In the one outlier, the first ENG 2010 survey, this task had the second-lowest confidence score. However, it differed from the task with the lowest confidence, Q20, by only 0.01 points.

In three of the four surveys where students were asked to rank their current level of proficiency (as opposed to speculating about their future expected proficiency at graduation), the task with the highest confidence score was the ability to continue "to learn and expand your knowledge after you complete your B.Sc. in Engineering" (Q19). Only the students surveyed for the second time in ENG 2010 reported slightly higher confidence levels in Q17.

When the ENG 2010 students were asked to speculate on their future expected proficiency at graduation, of the four lifelong learning tasks they predicted that "identifying the means to develop your strengths and eliminate your weaknesses" (Q18) would require the lowest relative level of proficiency. In all three capstone classes this was indeed the task with the lowest confidence score.

However, there was a discrepancy between the task that the ENG 2010 students predicted would require the highest level of proficiency at graduation, and the task with the highest relative confidence score in both capstone classes. The ENG 2010 students predicted that "applying critical inquiry and analysis to engineering problems and doing the communications that support the engineering work" (Q20) would require the highest level of proficiency upon graduation, while all three capstone classes reported the most confidence in the task of "continuing to expand your knowledge after you complete your B.Sc. in Engineering" (Q19).

It is a positive sign that students nearing graduation felt confident in their ability to perform this 
task, as it is arguably the one most directly linked to lifelong learning.

\section{CONCLUSION}

Given that the half-life of engineering information is only about $2-7$ years $^{8}$, at which time technical knowledge can begin to be less relevant ${ }^{9}$, engineering students must be prepared to develop the drive to keep learning. Technical and scientific publications double nearly every 10 years ${ }^{\mathbf{1 0}}$, so lifelong learning is even more critical to a professional engineer's success in an ever-changing, complex world. Both C.E.A.B. and A.B.E.T. have long recognized the importance of communication skills in the Engineering profession and, as a corollary, have likewise acknowledged that learning over a lifetime should never stop.

Our study suggests that students are at least aware of the need to continue learning and, concomitantly, developing and honing their own engineering knowledge. On the one hand, they were quite confident in their ability to work on developing broader knowledge, and only slightly less confident when asked about their ability to identify their personal strengths and weaknesses. On the other hand, and more telling perhaps, is their lower level of confidence when it comes to identifying ways to eliminate any weaknesses and to applying analysis to engineering problems and to the communications that support that work. As educators, we can help students develop ways that will then help them develop that confidence.

One way, for example, is by introducing students to practicing engineers, all of whom stress the ongoing importance of lifelong learning, and who can speak to ways that are useful to them. Another way is by instantiating reflective learning practices into courses like the Technical Communication course. Thus, we as educators can promote lifelong learning as a cornerstone of engineering practice and a critical imperative of the profession.

\section{Acknowledgements}

The authors wish to acknowledge the help and cooperation of the capstone coordinators who so generously allowed us to visit their classrooms and administer the surveys: Dr. Paul Labossiere, P.Eng. (Mechanical Engineering); Dr. Derek Oliver, P.Eng. (Electrical \& Computer Engineering); and Mr. David Amorim, P.Eng. (Civil Engineering).

The Ethics Review Board at the University of Manitoba has approved this study.

\section{References}

[1] A. Parker and K. Marcynuk, "The self-reported confidence and proficiency levels of undergraduate Engineering students in an engineering Technical Communication course," Proc. 2015 Canadian Engineering Education Association (CEEA15) Conf., McMaster University, May 31-June 3, 2015.

[2] A. Parker and K. Marcynuk, "The self-reported confidence and proficiency levels in communication skills: A comparison of undergraduate students in a Technical Communication course and senior capstone students," Proc. 2018 Canadian Engineering Education Association (CEEA-ACEG18) Conf., University of British Columbia, June 3-6, 2018.

[3] J.M. Twenge, W.L. Campbell and B. Gentile, "Generational increases in agentic self-evaluations among American college students, 1966-2009," Self and Identity, 11, pp.409-427, 2012.

[4] Engineers Canada Consultation Group on Engineering Instruction and Accreditation (Jan. 7, 2016). Graduate Attributes. Available: https://engineerscanada.ca/sites/default/files/GraduateAttributes.pdf [Accessed Nov. 14, 2019].

[5] J. Seniuk Cicek, S. Ingram and M.R Friesen, "On becoming an Engineer: The essential role of lifelong learning competencies," ASEE's $123^{\text {rd }}$ Annual Conference \& Exposition, New Orleans, LA, June 26-29, 2016. [Online]. Available: https://www.asee.org/public/conferences/64/papers/14631/ view [Accessed Nov. 5, 2019].

[6] S. Briggs, "Why self-esteem hurts learning but selfconfidence does the opposite," InformED, July 5, 2014. http://www.opencolleges.edu.au/informed/features/selfefficacy-and-learning [Accessed May 3, 2015].

[7] CDIO (Conceive Design Implement Operate). "3. Determining the appropriate levels of student proficiency for syllabus topics," 2008. Available: www.cdio.org/files/syllabus pt3.pdf . Accessed May 4, 2015.

[8] L. Jamieson, "Engineering education prepares for 2020," EE Times, Feb. 1, 2007 [Online], Available: https://www.eetimes.com/engineering-education-preparesfor-2020/\# [Accessed Jan. 13, 2020].

[9] E.T. Smerdon, "Lifelong learning for engineers: Riding the whirlwind," in The Bridge, vol. 26, no. 1/2 SpringSummer, 1996. [Online] Available: https://www.nae.edu/7596/LifelongLearningforEngineers RidingtheWhirlwind [Accessed Dec. 3, 2019].

[10] N. Asokan, “Characterization of Today's World.” Oct. 22 , 2016 [Online]. Available:

https://www.slideshare.net/AsokanNDr/today's-world67524647 [Accessed Dec, 3, 2019]. 